\title{
Fibroscan of Liver in Type 2 Diabetes Mellitus and Its Correlation with Risk Factors
}

\author{
Nikhil A. Kumar ${ }^{1}$, Sidhartha Das ${ }^{2}$ \\ ${ }^{1}$ Department of Medicine, SCB Medical College and Hospital, Cuttack, India \\ ${ }^{2}$ Department of Medicine and Dean and Principal, SCB Medical College and Hospital, Cuttack, India \\ Email: nikhilakmr@gmail.com
}

How to cite this paper: Kumar, N.A. and Das, S. (2019) Paper Title. Journal of Diabetes Mellitus, 9, 62-68. https://doi.org/10.4236/jdm.2019.92007

Received: March 29, 2019

Accepted: May 28, 2019

Published: May 31, 2019

Copyright $\odot 2019$ by author(s) and Scientific Research Publishing Inc. This work is licensed under the Creative Commons Attribution International License (CC BY 4.0).

http://creativecommons.org/licenses/by/4.0/

(c) (†) Open Access

\begin{abstract}
Introduction: Non-alcoholic fatty liver disease (NAFLD) is regarded as the hepatic manifestation of metabolic syndrome. Insulin resistance is regarded as central to the development of NAFLD. Type 2 Diabetes Mellitus (DM) is an important cause of NAFLD. The pathology in NAFLD ranges from hepatic steatosis, non-alcoholic steatohepatitis (NASH), cirrhosis and primary liver cancer. Diagnosis of NAFLD requires demonstration of increased liver fat in the absence of hazardous levels of alcohol consumption. Liver biopsy is the gold standard for diagnosis of NAFLD but it is fraught with various difficulties and is a risky procedure. Fibroscan $\left({ }^{\circledR} \mathrm{Abbott}\right)$ or transient elastography is a non-invasive tool which measures the hepatic stiffness. Objective: To estimate the degree of hepatic stiffness due to NAFLD and to identify the factors affecting it. Patients: 50 patients of newly diagnosed Type 2 diabetes mellitus without a history of chronic hepatitis or alcohol intake were included in the study. Results: In our study, $40 \%$ of the patients were obese with $46 \%$ of the total patients having an elevated AST, 66\% having an elevated ALT and 18\% having an elevated alkaline phosphatase. Dyslipidemia was very common with $14 \%$ of total patients having a high cholesterol, $36 \%$ having elevated triglycerides, $64 \%$ having a low HDL with none with an elevated LDL. $50 \%$ of patients had steatosis on ultrasound. On comparing liver stiffness, a significantly high hepatic stiffness $(>7.9 \mathrm{kPa})$ was found in $34 \%$ of patients with severe fibrosis $(\geq 12 \mathrm{kPa})$ in $10 \%$ of patients. Multivariate analysis showed significant positive correlation of fibroscan value with total cholesterol and ALT levels and there was a significant negative correlation with AST levels and serum HDL levels. Conclusion: Fibroscan may be helpful in diagnosing and guiding treatment of NAFLD. Larger studies to evaluate its efficacy in determining prognosis of NAFLD are warranted.
\end{abstract}

\section{Keywords}

Diabetes Mellitus, NAFLD, Fibroscan, Transient Elastography, NASH 


\section{Introduction}

Non-alcoholic fatty liver disease (NAFLD) refers to the accumulation of fat (mainly triglycerides) in hepatocytes that result from insulin resistance. The spectrum of NAFLD includes hepatic steatosis, non-alcoholic steatohepatitis (NASH), cirrhosis and hepatocellular carcinoma. Type $2 \mathrm{DM}$ is an important risk factor for the development of NAFLD. Hyperinsulinemia which occurs as a result of insulin resistance increases the intra-hepatocytic fatty acids by increasing the glycolysis and decreasing the apolipoprotein B-100 which results in decreased export of VLDL. Most patients with NAFLD are asymptomatic and may have elevation of liver enzymes which is noted incidentally in biochemical investigations. Alanine amino transferase (ALT) and aspartate amino transferase (AST) are usually elevated, but these levels do not reliably correlate with hepatic injury, inflammation or cirrhosis in NAFLD [1]. Fibrosis staging is important in all patients with NAFLD to identify patients with advanced hepatic fibrosis at risk of liver-related complications, hepatocellular dysfunction and portal hypertension resulting from advancing hepatic fibrosis. Although liver biopsy remains the gold standard for NAFLD, it is an invasive procedure and has to be done at regular intervals to know the progression of NAFLD. Many non-invasive tests have been developed for this purpose like transient elastography (TE), magnetic elastography (ME), acoustic radiation force impulse (ARFI) etc. Out of these, transient elastography (TE), more commonly known as FibroScan, is the most commonly used. In this technique, a $50-\mathrm{MHz}$ wave is passed into the liver from a small transducer on the end of an ultrasound probe. The probe also has a transducer on the end that can measure the velocity of the shear wave. Essentially, the technology measures the velocity of the sound wave passing through the liver and then converts that measurement into a liver stiffness measurement (LSM) which is measured in kiloPascals ( $\mathrm{kPa}$ ). The LSM correlates well with the degree of liver fibrosis in a wide range of liver diseases, including NAFLD [2]. The present study aims to study the degree of liver stiffness and the factors affecting LSM in patients of type 2 DM attending a tertiary care hospital in Cuttack, India.

\section{Methods}

\subsection{Study Design}

This study was a facility-based observational study.

\subsection{Patient Selection}

The study included newly diagnosed patients of Type $2 \mathrm{DM}$ attending the General Medicine OPD of SCB Medical College and Hospital between July 2018 and December 2018. Patients with history of alcohol intake, acute or chronic hepatitis, ascites, morbid obesity, gestational DM, type $1 \mathrm{DM}$ and secondary diabetes were excluded from the study. 


\subsection{History Taking and Procedures}

Medical history was obtained from all patients including history regarding alcohol use. Height and weight were recorded. Ultra-sound of abdomen was done to diagnose of hepatic steatosis. Aspartate transaminase (AST), Alanine transaminase (ALT), alkaline phosphatase and lipid profile (consisting of LDL, HDL, serum triglycerides and total cholesterol) were estimated by spectrophotometric method using autoanalyzer without regard to time since last meal. All patients were subjected to transient elastography or FibroScan $\left({ }^{\circ}\right.$ EchoSens, Abbott) using a 50-MHz transducer standard $\mathrm{M}$-probe in our gastroenterology department. At least 10 readings were obtained by placing the transducer in the liver area. A $60 \%$ success rate with an interquartile range of $\leq 30 \%$ was defined as the criteria for a reliable measurement. The median FibroScan value displayed on the screen was taken as the result of the test and was used for analysis.

\subsection{Statistical Analysis}

The data was entered in MS EXCEL spreadsheet and master table was created. Analysis was done using Statistical Package for Social (SPSS) version 25. Chi-Square test was used for qualitative data and Student's t-test was used for quantitative data.

\section{Observations}

50 Newly diagnosed patients of Type 2 DM were included in the study. Most of the patients were in the age group 40 to 49 years (38\%). 64\% were males and $36 \%$ were females. $40 \%$ patients were obese defined as BMI more than or equal to $30 \mathrm{~kg} / \mathrm{m}^{2}$.

In our study, the patients were categorized into groups based on cut-offs for fibrosis proposed by Wong et al. [3]. This is also given in the official physician information sheet provided along with the FibroScan.

Group 1: 0 to $5.8 \mathrm{kPa}$

Group 2: 5.8 to $6.8 \mathrm{kPa}$

Group 3: 6.8 to $7.8 \mathrm{kPa}$

Group 4: 7.8 to $11.8 \mathrm{kPa}$

Group 5: $>11.8 \mathrm{kPa}$

Figure 1 shows the distribution of liver stiffness measurements among the studied patients. Most people had LSM in the range of 0 to $5.8 \mathrm{kPa}(34 \%)$, followed by 6.8 to $7.8 \mathrm{kPa}$ and 7.8 to $11.8 \mathrm{kPa}$ (11\% each).

Table 1 shows the results of multivariate regression analysis comparing association of age, weight, AST, ALT, ALP, total cholesterol, LDL, HDL and triglycerides with FibroScan score. Among these factors, significant positive correlation of liver stiffness was found with ALT \& total cholesterol with p-value of 0.001 and 0008 respectively and significant negative correlation was found with HDL and AST, with a p-value of 0.008 and 0.001 respectively. 


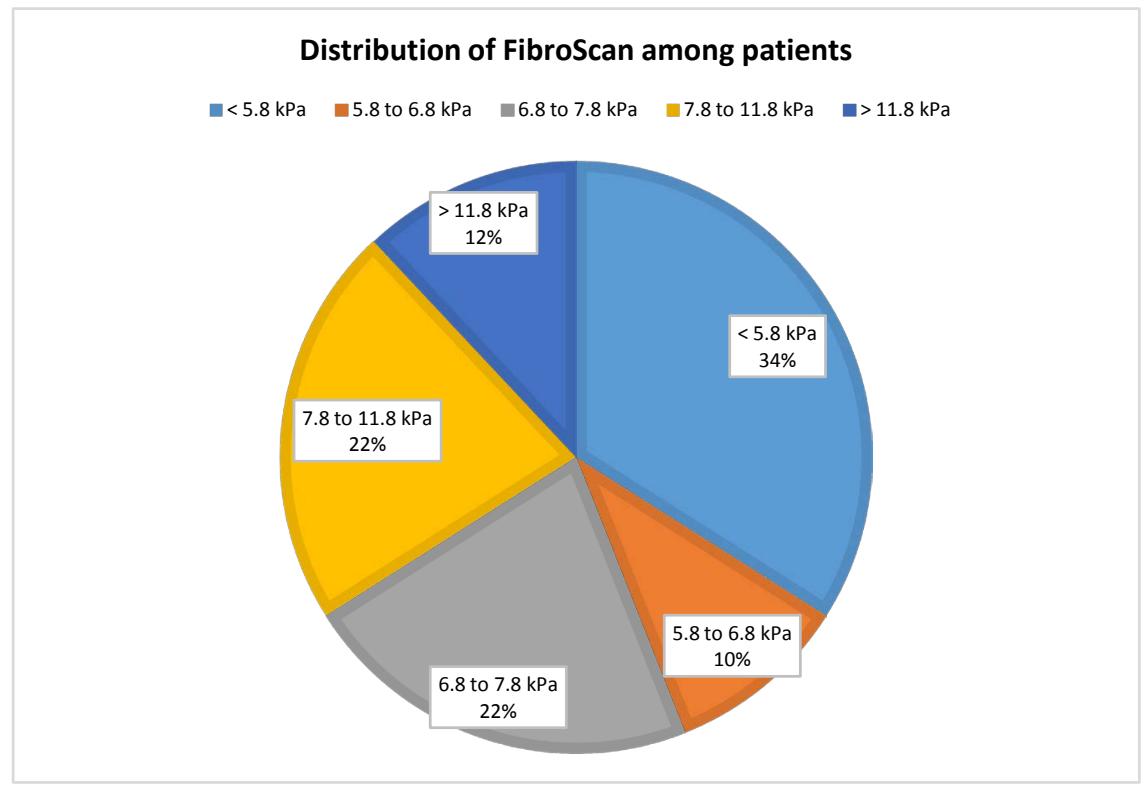

Figure 1. Figure showing distribution of Fibroscan values among patients.

Table 1. Results of multivariate analysis showing association of various parameters with Fibroscan score.

\begin{tabular}{|c|c|c|c|c|c|c|}
\hline \multirow{2}{*}{ Variable } & \multicolumn{2}{|c|}{$\begin{array}{l}\text { Unstandardized } \\
\text { Coefficients }\end{array}$} & \multirow{2}{*}{$\begin{array}{l}\text { Regression } \\
\text { Coefficient } \beta\end{array}$} & \multirow{2}{*}{$\mathrm{p}$-Value } & \multicolumn{2}{|c|}{$\begin{array}{l}95.0 \% \text { Confidence Interval } \\
\text { for } \beta\end{array}$} \\
\hline & B & $\begin{array}{l}\text { Std. } \\
\text { Error }\end{array}$ & & & $\begin{array}{l}\text { Lower } \\
\text { Bound }\end{array}$ & Upper Bound \\
\hline (Constant) & 0.505 & 3.612 & - & 0.889 & -6.794 & 7.805 \\
\hline Age & -0.022 & 0.048 & -0.053 & 0.656 & -0.12 & 0.076 \\
\hline Weight (kg) & 0.069 & 0.034 & 0.218 & 0.051 & 0 & 0.139 \\
\hline AST (U/L) & -0.082 & 0.021 & -0.584 & 0.001 & -0.125 & -0.038 \\
\hline ALT (U/L) & 0.105 & 0.019 & 0.86 & 0.001 & 0.067 & 0.143 \\
\hline $\operatorname{ALP}(\mathrm{U} / \mathrm{L})$ & 0.004 & 0.004 & 0.11 & 0.322 & -0.004 & 0.012 \\
\hline $\begin{array}{l}\text { Total cholesterol } \\
\text { (mg \%) }\end{array}$ & 0.019 & 0.007 & 0.328 & 0.008 & 0.005 & 0.032 \\
\hline LDL (mg \%) & 0.017 & 0.014 & 0.132 & 0.256 & -0.013 & 0.046 \\
\hline HDL (mg \%) & -0.094 & 0.033 & -0.342 & 0.008 & -0.161 & -0.026 \\
\hline TG (mg \%) & 0 & 0.004 & -0.01 & 0.931 & -0.008 & 0.008 \\
\hline
\end{tabular}

Table 1 shows the association of age, weight, AST, ALT, ALP, total cholesterol, LDL, HDL and triglycerides with FibroScan score. Among these factors, significant positive correlation of liver stiffness was found with ALT \& total cholesterol with p-value of 0.001 and 0008 respectively and significant negative correlation was found with HDL and AST, with a p-value of 0.008 and 0.001 respectively. (B refers to coefficient of regression of unstandardized variables and $\beta$ refers to the coefficient of regression after standardization).

\section{Discussion}

\subsection{Study Findings}

The term non-alcoholic fatty liver disease (NAFLD) is commonly categorized by 
accumulation of fat in liver which changes from simple steatosis to steatohepatitis, cirrhosis and hepatocellular carcinoma (HCC) in lack of excessive alcohol intake. NAFLD is the most common cause of persistently abnormal liver enzymes (AST and ALT). Type 2 Diabetes Mellitus (T2DM) patients seem to have an enlarged risk of developing NAFLD than non-diabetic subjects and certainly have higher risk of increasing fibrosis and cirrhosis. T2DM surges the risk of liver associated death by up to 22 -fold in patients with NAFLD [4]. The prevalence rate of NAFLD in T2DM is estimated to be in the range of $12.5 \%$ to $87.5 \%$ in India [5]. A large number of patients of NAFLD have a normal liver enzyme profile and the entire histologic spectrum of NAFLD may be seen in such patients.

In a study by Salmela P.I. et al., 57\% patients of diabetics had at least one abnormal LFT and 27\% gave 2 abnormal LFT [6]. More recently, a study by Rashid MHO et al. showed that $58 \%$ of diabetics had at least one abnormal liver enzyme and all patients had mild elevation [7]. In our study, $46 \%$ of total patients had a raised AST, $66 \%$ had an elevated ALT and 6\% had an elevated alkaline phosphatase. Most of the patients had a mild elevation of AST and ALT (up to $\times 2$ times normal).

Different researchers have used different cut-offs for studying the role of FibroScan in NAFLD. The following table summarizes the different studies and the cut-offs used:

\begin{tabular}{|c|c|c|c|}
\hline Study & $\begin{array}{l}\text { Cut-off of FibroScan } \\
\text { used for further study }\end{array}$ & $\begin{array}{l}\text { Proportion of patients } \\
\text { with significant fibrosis }\end{array}$ & $\begin{array}{l}\text { Fibrosis } \\
\text { confirmed by }\end{array}$ \\
\hline $\begin{array}{l}\text { Ledinghen } \\
\mathrm{V} \text { et al. [8] }\end{array}$ & $\begin{array}{l}8.7 \mathrm{kPa} \\
\text { (for severe fibrosis) }\end{array}$ & $15.5 \%$ & FibroTest \\
\hline $\begin{array}{l}\text { Wong } \\
\text { et al. [2] }\end{array}$ & $\begin{array}{l}7.9 \mathrm{kPa} \\
\text { (for significant fibrosis or } \mathrm{F} 2 \text { ) }\end{array}$ & $39.8 \%$ & Liver biopsy \\
\hline $\begin{array}{l}\text { Cassinoto } \\
\text { et al. [9] }\end{array}$ & $\begin{array}{l}6.3 \mathrm{kPa} \\
\text { (for significant fibrosis or F2) }\end{array}$ & $70.8 \%$ & $\begin{array}{l}\text { Supersonic shearwave } \\
\text { imaging (SSI), Acoustic } \\
\text { radiation force impulse } \\
\text { imaging (ARFI), liver biopsy }\end{array}$ \\
\hline
\end{tabular}

Using a cut-off of $7.9 \mathrm{kPa}$ as suggested in a study by Wong et al. [2], 34\% of our patients had a significant liver stiffness which is similar to the value of $39.8 \%$ reported by him (Figure 1). Thomas et al. showed that $68.3 \%$ diabetics had significant fibrosis [10]. Out of the patients having significant fibrosis $(>7.9 \mathrm{kPa})$, males constituted $76.5 \%$ and females $23.5 \%$. Severe fibrosis (LSM $\geq 12 \mathrm{kPa}$ ) was seen in $10 \%$ of patients of diabetes with males forming $10 \%$ and females forming the rest $80 \%$.

On multivariate analysis of factors affecting fibroscan score in our study, we found significant positive correlation of fibroscan value with total cholesterol and ALT levels (Table 1) and there was significant negative correlation with AST levels and serum HDL levels. Hajiani E et al. found that there was correlation between triglycerides and AST with FibroScan values; there was no differ- 
ence in age, BMI, ALT, LDL or fasting blood sugar among the groups of patients divided on the basis of FibroScan values [11]. In a study by Lallukka, S. et al., they concluded that waist circumference and plasma ALT were significant and independent predictors of high fibroscan value [12]. The negative correlation of AST with fibroscan value may be because of the fact that AST elevation is not specific to liver disease. ALT levels predict liver injury better.

\subsection{Conclusion}

NAFLD is an important but often overlooked disease. Management of NAFLD requires knowledge of its stage. Our study shows that diabetics have a higher degree of liver stiffness, many of whom remain undetected by routine liver enzyme tests and USG. Dyslipidemia (especially high serum total cholesterol and low serum HDL) predicts a high degree of liver stiffness and such patients should be subjected to periodic LSM measurements to record the progression. Newer non-invasive tests like magnetic elastography (ME), acoustic radiation force impulse imaging (ARFI), controlled attenuation parameter (CAP) as well as blood markers like cytokeratin 8 may eventually replace liver biopsy. Large scale studies comparing their efficacy should be done and newer guidelines may need to be developed.

\section{Acknowledgements}

The authors would like to thank Dr. C.R. Panda, Professor and HOD, Department of Gastroenterology, SCB Medical College for his help and guidance.

\section{Conflicts of Interest}

The authors declare no conflicts of interest regarding the publication of this paper.

\section{References}

[1] Mofrad, P., Contos, M.J., Haque, M., Sargeant, C., et al. (2003) Clinical and Histologic Spectrum of Nonalcoholic Fatty Liver Disease Associated with Normal ALT Values. Hepatology, 37, 1286-1292. https://doi.org/10.1053/jhep.2003.50229

[2] Foucher, J., Chanteloup, E., Vergniol, J., et al. (2006) Diagnosis of Cirrhosis by Transient Elastography (FibroScan): A Prospective Study. Gut, 55, 403-408. https://doi.org/10.1136/gut.2005.069153

[3] Wong, V.W., Vergniol, J., Wong, G.L., Foucher, J., Chan, H.L., et al. (2010) Diagnosis of Fibrosis and Cirrhosis Using Liver Stiffness Measurement in Nonalcoholic Fatty Liver Disease. Hepatology, 51, 454-462. https://doi.org/10.1002/hep.23312

[4] Younossi, Z.M., Granlich, T., Matteoni, C.A., Boparai, N. and McCullough, A.J (2004) Non-Alcoholic Fatty Liver Disease in Patients with Type 2 Diabetes. Clinical Gastroenterology and Hepatology, 2, 262-265. https://doi.org/10.1016/S1542-3565(04)00014-X

[5] Prashanth, M., Ganesh, H.K., Vima, M.V., John, M., Bandgar, T., Joshi, S.R., et al. (2009) Prevalence of Nonalcoholic Fatty Liver Disease in Patients with Type 2 Diabetes Mellitus. Journal of the Association of Physicians of India, 57, 205-210. 
[6] Salmela, P.I., Sotaniemi, E.A., Niemi, M. and Mäentausta, O. (1984) Liver Function Tests in Diabetic Patients. Diabetes Care, 7, 248-254.

https://doi.org/10.2337/diacare.7.3.248

[7] Rashid, M.H.O., Haque, M.Z., Rahman, M.K., Khan, M.M.R., Rahman, A.S.M.M., Al-Mahtab, M., Rahman, M.S., Roy, P.K. and Islam, M.N. (2016) Study on Liver Dysfunction in Type 2 Diabetic Patients in Bangladesh. Euroasian Journal of Hepato-Gastroenterology, 6, 1-4.

[8] Ledinghen, V., Vergniol, J., Gonzales, C., et al. (2004) Screening for Liver Fibrosis by Using FibroScan ${ }^{\circledast}$ and FibroTest ${ }^{\oplus}$ in Patients with Diabetes. Digestive and Liver Disease, 44, 413-414. https://doi.org/10.1016/j.dld.2011.12.005

[9] Cassinotto, C., Boursier, J., Lédinghen, V., Lebigot, J., Lapuyade, B., Cales, P., Hiriart, J., Michalak, S., et al. (2016) Liver Stiffness in Nonalcoholic Fatty Liver Disease: A Comparison of Supersonic Shear Imaging, FibroScan, and ARFI with Liver Biopsy. Hepatology, 63, 1817-1827. https://doi.org/10.1002/hep.28394

[10] Thomas, P.A. (2017) Fibroscan to Detect Significant Fibrosis in NAFLD. Journal of Clinical and Experimental Hepatology, 7, S40.

https://doi.org/10.1016/j.jceh.2017.05.077

[11] Hajiani, E., et al. (2014) Comparison of the Transient Elastography (Fibroscan) Results among Diabetic and Non-Diabetic Patients with Non-Alcoholic Fatty Liver Disease. Gastroenterol Hepatol Open Access, 1, Article ID: 00021. https://doi.org/10.15406/ghoa.2014.01.00021

[12] Lallukka, B., Susanna, S., Sanja, T., Kallio, M.T. et al. (2017) Predictors of Liver Fat and Stiffness in Non-Alcoholic Fatty Liver Disease (NAFLD)-An 11-Year Prospective Study. Scientific Reports, 7, Article ID: 14561. https://doi.org/10.1038/s41598-017-14706-0 